\title{
The Concept of Creating the Universal Life-Saver with Rotary-Screw Mover
}

\author{
Alla Koshurina, Maxim Krasheninnikov, Viktor Shapkin, Roman Dorofeev, Valentina Obrezkova \\ Institute of Transport Systems \\ Nizhny Novgorod State Technical \\ University named after R.Y. Alekseev (NNSTU), Russian Federation
}

\begin{abstract}
At the present time there is active development of oil and gas fields located offshore in the northern seas. Mineral resources are mined in severe natural and climatic conditions. These conditions complicate platforms' accordance to high safety requirements to various industrial processes. Moreover, according to the analysis of the accidents, there is a problem in providing fast reliable and efficient evacuation of the platform's personnel. Present means of evacuation cannot work effectively under such difficult conditions. This paper shows the analysis of accidents that occurred on the platforms, neviews existing means of evacuation, and indicates solutions to some actual safety problems. This paper offers a versatile rescue tool with rotaryscrew propeller, which can effectively overcome various environments. Features of rotary-screw mover allow to use technological and transport means in such areas where the usage of other movers is impossible or irrational. However, the creation of such devices is possible only with relevant research; such studies are conducted by Nizhny Novgorod State Technical University named after R.Y. Alekseev.
\end{abstract}

Keywords-methodology, simulation; optimization; rescue vehicles; (rotary-) screw mover

\section{INTRODUCTION}

Currently about $35 \%$ petroleum and $32 \%$ of gas produced in the world occur in the offshore fields [6]. Since oil and gas reserves on the continental fields has been steadily decreasing, becomes more urgent question of oil and gas production is from offshore fields [1].

Work on these platforms is more dangerous than on ground complexes. It is connected with more severe conditions in which minerals are extracted and damage of larger area in case of accident. In ensuring the safety of these facilities the most important role is played by technical and technological innovations, as well as modern systems of regulation and organization of work. Probability of occurrence of major accidents calls for a reliable evacuation of personnel platforms. Review of major accidents in the oil and gas platforms will determine the prevailing risk factors that need special attention when designing life-saving equipment [2].

\section{MACHINES FOR THE SALVATION OF MEN IN THE OIL AND GAS PLATFORMS}

It is known that the most promising water areas on the possibility of creating oil and gas production facilities are the arctic seas, which accounts for more than $85 \%$ of potential oil and gas resources [3]. The main areas of hydrocarbon resources concentration are the Barents Sea (3.8 billion tons), Kara Sea (4.7 billion tons), the East Siberian Sea (2.1 billion tons) and the Sea of Okhotsk (2.1 billion tons) [3].

Characteristics of the particular conditions of Russian oil and gas platforms may be shown on the example of the Shtokman field (Fig. 1) in the Barents Sea. Compilation of various organizations' data allows us to formulate the set of operating conditions in a field for a machine to work. Distance to the continent $680 \mathrm{~km}$; water depth $320-350 \mathrm{~m}$; duration of the polar day, 102 days; low visibility due to fog, precipitation, blowing snow and low clouds; maximu $\mathrm{m}$ wind speed $49 \mathrm{~m} / \mathrm{s}$; fluctuations in water level from +90 to $-125 \mathrm{~cm}$; maximum flow rate: $0.9 \mathrm{~m} / \mathrm{s}$ - on the surface and $0.3 \mathrm{~m} / \mathrm{s}$ - at the bottom; the maximu mave height $24 \mathrm{~m}$; the maximum ice thickness $1.2 \mathrm{~m}$. At operation of drilling equipment icebergs posing a danger must to blow or take a way to the side to avoid collision with the rigs.

Requirements to platforms are determined by external conditions of their operation (Fig. 2) [5]. Meeting these requirements is instrumental to the optimality of designing, technical and environmental safety, and general decline the cost of field development.

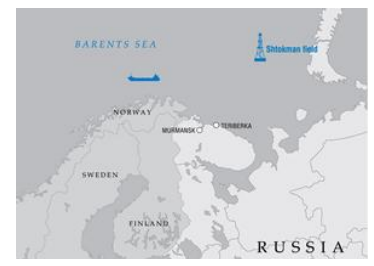

FIGURE I. ARRANGEMENT OF THE SHT OKMAN FIELD.

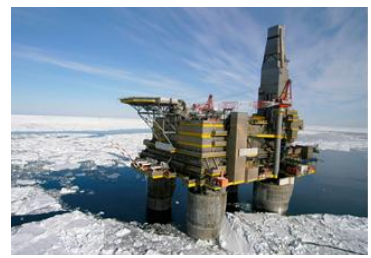

FIGURE II. OIL AND GAS PLATFORM IN THE ICE COVER.

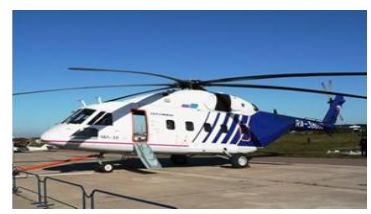

FIGURE III. AERIAL EVACUATION MEANS. 


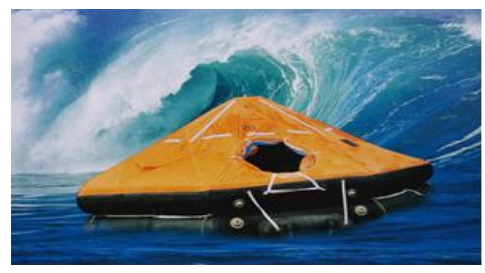

FIGURE IV. AN EXAMPLE OF AN INFLATABLE LIFE RAFT FOR EVACUATION.

The usage of life rafts (Fig. 4), together with a special system of lowering, will also be ineffective, because these rafts could not move in the arctic seas and ensure the necessary level of safety.

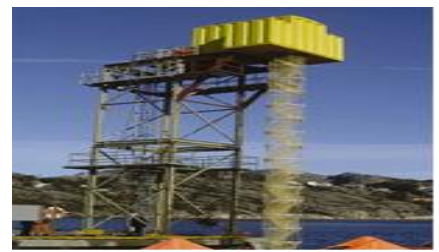

FIGURE V. MEANS OF TRANSPORTINGPEOPLE FROM THE PLATFORM ONTO LIFE RAFT S.

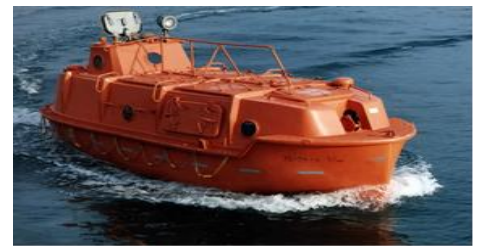

FIGURE VI. LIFEBOAT S

The use of lifeboats (Fig. 6) will be limited because of their functional limitation of motion in the water, as well as a high probability of freezing in case the boat stops. They need to bypass the ice fields, which is not always possible.

Consequently, there is a need to develop lifesaving equipment, adapted to the northern seas.

Requirements for this lifesaving equipment have been formulated taking into account the external conditions of Russian oil and gas platforms. In general, lifesaving equipment for the Arctic must:

1. Operate under low temperatures, ice, gusty wind, storms and poor visibility;

2. Owning a high passableness in different environments and amphibious qualities;

3. Have a large reserve buoyancy and stability curve;

4. Be able to overcome the stains of burning oil;

5. To support the regime autonomous work to several days.

In this situation it is necessary to consider the usage of vehicles, movers of which have distinguishing characteristic: interaction with a supporting surface. Among the floating machines mach ine with rotary-screw mover (RSM) occupies a special place. Features of rotary-screw mover allow to use technological and transport means in such areas where the usage of other movers is impossible or irrational. The rotary- screw mover would allow movement in freezing water in the course of year and evacuate people in case of accidents in the arctic regions (Fig. 7).

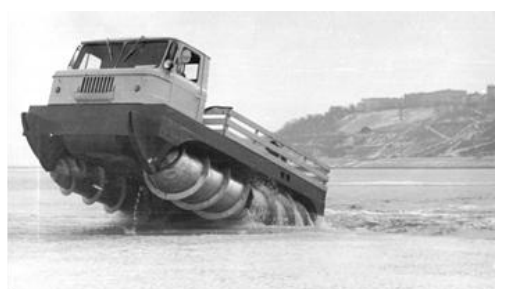

FIGURE VII.OUTPUT ON THE ICE ROTARY-SCREW VEHICLE GPI-72.

RSM combines the quality of hydraulic movers and onshore movers and can work effectively in the highly moistened soil, snow, ice, water and in the environment, which is a combination of these surfaces. The rotary-screw mover is used for different machines - road construction, agricultural, military, etc. For example, in Russia, this mover is used in heavy and powerful mach ines for cutting the ice and in light cross-country vehicle. In the United States - on military armored personnel carriers to move through the swamps and flooded fields. In Poland, this mover is used on a special towing vehicle for movement on a thick layer of silt on fish farms. In Japan, they produce life-saving and recreational vehicles with rotary-screw mover.

In particular, the Japanese company Mitsui built a few rotary-screw vehicles (RSV), one of which is specially designed for the movement in Arctic ice off Alaska. Testing has shown that the machine on ice thickness of $30 \ldots 50 \mathrm{~cm}$ reached the highest maximu $m$ traction ratio (the ratio of thrust to weight ratio) was equal to $45 \%$ at an inclination of the helical blade 30 degrees and at a ratio of height of the helical blade to diameter of base cylinder 0.15 . The machine had a mass of 10.8 tons and a length of $7 \mathrm{~m}$. The engineers of Mitsui give the following results: the machine can tow loads of 200 tons on water at a speed of 3 knots, on the ice - a speed of 25 . 40 knots, the machine can move in ice covered with water at $50 \mathrm{~cm}$, where any other machine and ships cannot move, the mach ine breaks the ice thickness up to $43 \mathrm{~cm}$.

Compared with the other types of ground movers the rotary-screw mover has many advantages [4]:

1. Ensures particularly high cross -country ability;

2. Shows a very low ground pressure;

3. Develops huge traction force;

4. Provides going out to ice and unequipped shore.

Experience of using the rotary-screw mover on the amphibious transport and technological machines and icebreaking machines indicates the perspective of a universal life-saver development to help the distressed vessel crews and staff of ice-resistant stationary platforms.

But the creation of such vehicles for movement in difficult conditions (non-cohesive grounds, snow, ice, water and a combination of these media) is impossible without research in relevant fields. 
In Fig. 8 and 9 shown the developed in NNSTU project of universal life-saver with RSM and conditions of use.

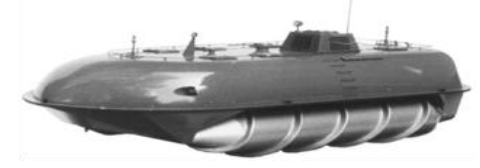

FIGURE VIII. MODEL OF THE UNIVERSAL LIFE-SAVER WITH ROT ARY-SCREW MOVER.

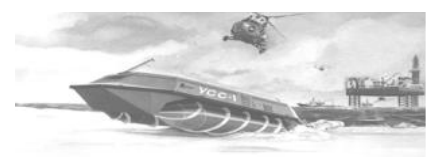

FIGURE IX. ILLUST RATION OF THE OPERATING CONDITIONS OF THE UNIVERSAL LIFE-SAVER WITH ROTARY-SCREW MOVER.

The basic concept of universal life-saver was formulated after review of existing lifesaving devices and after determining the operating conditions in the Arctic shelf.

The machine can move across the area of burning oil due to the hulls isolated by heat-resistant tiles. Such tiles are used on the hulls of space shuttles. The setting is determined by the systems of technical vision. Autonomous work for several days is achieved through the use of life support systems.

But this project was completed more than 20 years ago and its result cannot be considered as the best possible technical solution. The process of creating a new improved model of the universal life-saver with rotary-screw mover will include the following steps:

1. Model of interaction of RSM with different grounds;

2. Correction the model of experiments;

3. Creation a model of RSV movement in different environments;

4. Tests of samples of RSV and correction models of motion; RSM;

5. Determination of optimal parameters of the RSV and

6. Create a prototype;

7. Analysis of the prototype. Design and manufacture the Universal life-saver with rotary-screw mover.

Projecting according to the stages will allow creating lifesaver with screw mover in accordance with safety require ments (Fig. 10).

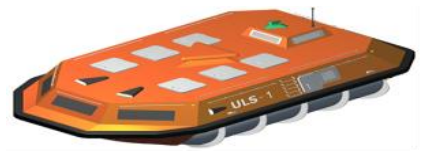

FIGURE X. THE GENERAL FORM OF CONCEPTUAL DESIGN THE MACHINETOTHE RESCUE PERSONNEL ICE-RESIST ANT OIL AND GAS PLATFORMS.

As can be seen from the general sequence of design stages, firstly, goes the creating of a mathematical model of the different processes and then goes their adjusting. This will help to achieve two goals: first to develop and verify in practice the theory of motion of rotary-screw vehicles, and secondly receive, valuable information and recommendations necessary for the design of modern machines special purpose thanks to this theory.

Model of the rotor will be the set of equations of its surfaces.

It is advisable to divide the surface model by the following parts: the surface of the base of the cylinder, the of the screw blade, the surface of the tip of the rotor (with screw blade and without) the surface of the ends of the rotor, middle surface to describe the two-cylinder rotor (Fig. 7). This decomposition allows obtaining a very accurate description of the rotor surface.

In addition to the separation of one-and two-cylinder rotaries, this mover can have different end caps (conical, spherical, parabolic shape, as well as their combinations), different blade sectional view (triangular, trapezoidal and sheet) and may contain up to 3-4 helical blades .

In general, the model of the rotary-screw mover, such as single-cylinder (Fig. 11), is a particular case of the helicoid equation. The surface is determined by a system of parametric equations (for a Cartesian coordinate system) of the following form:

$$
\left\{\begin{array}{l}
X=f(r) \cdot \cos [f(P)], \\
Y=f(r) \cdot \sin [f(P)], \\
Z=f(h) \cdot \frac{f(P)}{2 \cdot \pi} .
\end{array}\right.
$$

$f(r)$ - function of changing the distance from the axis of symmetry;

$\mathrm{r}$ - the specified range of the radius;

$\mathrm{f}(\mathrm{h})$ - function changes the height of the being constructed figure;

$\mathrm{h}$ - range of changes of height;

$f(P)$ - function that determines the shape of the figure in the plane perpendicular to the axis of symmetry;

$\mathrm{i}, \mathrm{j}$ - the parameters of the equation, which are not shown in the formula of general form.

In particular, the system of parametric equations which describes the surface of one side of the helical blade (Fig. 12) looks like:

$$
\left\{\begin{array}{l}
X=(r+h \cdot i) \cdot \cos \left(\frac{L_{B}}{P} \cdot 2 \pi \cdot j-\frac{t_{O}-t_{B}}{P} \cdot \pi \cdot i\right), \\
Y=(r+h \cdot i) \cdot \sin \left(\frac{L_{B}}{P} \cdot 2 \pi \cdot j-\frac{t_{O}-t_{B}}{P} \cdot \pi \cdot i\right), \\
Z=L_{H}+L_{B} \cdot j .
\end{array}\right.
$$

$\mathrm{r}$ - radius of basic cylinder; $\mathrm{h}$ - height of helical blade; LБ - length of basic cylinder; $\mathrm{P}$ - pitch of helical blade; tO - 
thicknes s of helical blade at the base; tB - thickness of helical blade at the vertex; LH - length of part of the screw head.

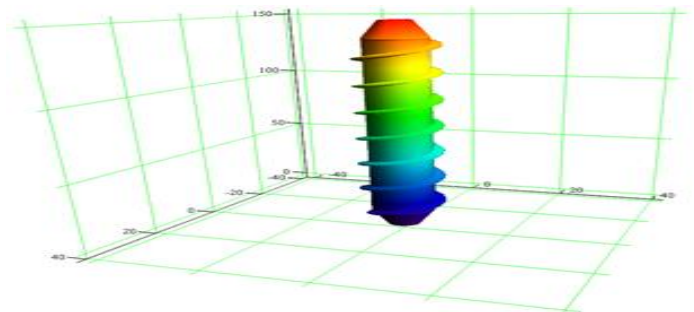

FIGURE XI. THE RESULT OF THE CONST RUCTION OF THE SURFACE SINGLE-CYLINDER SCREWS ONTHE BASIS OF THE PARAMETRICEQUATIONS.

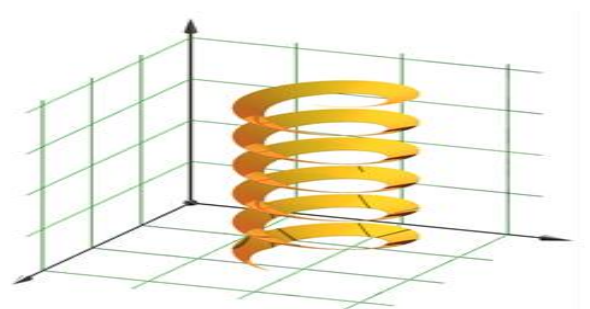

FIGURE XII.THE SURFACE OF ONE SIDE OF THE HELICAL BLADE.

At the moment created a mathematical model describing the shape of the screw mover which allows you to vary any desired parameter such as length and diameter of the base of the cylinder, the shape and size profile of the helix, the angle of winding and many others. Later will determine the choice of models used to describe the different environments and make their association with the model of the screw mover to describe the processes occurring in the contact zone of mover with a support base.

\section{CONCLUSION}

This paper is devoted the creation of universal life-saver for severe conditions of the Arctic shelf. The conclusion was made after analysis of the natural conditions that the modern means of salvation are not suitable for the Arctic shelf. The concept of universal life-saver with rotary-screw mover was proposed. The mathe matical model of motion the rotary-screw vehicle was created to determine the optimal parameters of this mover.

\section{ACKNOWLEDGEMENT}

This work was carried out at the NSTU named after R.E. Alekseev, with financial support from the government in the face of the Russian Ministry of Education under the Federal Program "Research and development on priority directions of the scientific-technological co mplex of Russia for 2014-2020", the unique identifier of the project: RFMEFI57714X0105.

\section{REFERENCES}

[1] Around the World [electronic resource]: [official. site]. - Electronic dat a. Mode of access: http://www.vokrugsveta.ru/vs/article/2938/, free

[2] Bekker MG «Introduction to terrain-vehicle systems: Trans. from English» /Ed. Guskov VV. - Moscow. Mashinostroenie, 1973. - 520.

[3] Bohatyryova EV «Methods of ensuring the safety of oil and gas platforms of the Arctic shelf: Dissertation of candidate of technical sciences» - Moscow, 2004.
[4] Kulashov AP, Shapkin VA, Donato IO and others «Screw machine. Fundamentals of the theory of motion». Nizhny Novgorod: NNSTU, 2000. - 451 .

[5] Mokrousov $\mathrm{SN}$ «Security issues in the development of oil and gas resources on the continental shelf and on land of the Russian Federation» / / Journal-directory "Transport security and technology." 2006. - № 1 .

[6] Osadchy A «Oil and Gas of the Russian Shelf: estimates and projections» / / Journal "Science and Life." - 2006. - № 7. 